\title{
"FAMIGERADO": UM DESAFIO PARA O TRADUTOR
}

\author{
Anelise Chemin Leopolski ${ }^{1} e$ \\ Mariana Sbaraini Cordeiro ${ }^{2}$
}

\begin{abstract}
RESUMO: Os Estudos de Tradução possibilitam responder a questões que surgem quando lemos Guimarães Rosa, pois como leitores em nossa língua-cultura, a obra de Rosa nos inquieta quando nos deparamos com a sua linguagem: uma construção da sintaxe um tanto quanto diferente e a presença de neologismos. Conhecendo a língua inglesa e também um pouco de sua cultura, questionamonos como seria possivel transpor alguns desafios peculiares à linguagem rosiana. Assim, neste estudo, analisaremos como isso acontece na única tradução para o inglês do conto "Famigerado", de Barbara Shelby, em 1968. Ao fragmentar a linearidade das frases, isso sugere a descontinuidade do tempo ou da linguagem oral, além de criar uma pontuação também única na versão para a língua inglesa. De que maneira essa singularidade rosiana foi traduzida? Como foi feita a tradução de trechos peculiares de Rosa, por exemplo, "Se sério, se era. Transiu-se$m e$ "? A sintaxe rosiana se faz notável na versão em inglês ou ela se perdeu no processo da tradução? Para nos imbricarmos na tentativa de buscar resposta a esses questionamentos, apropriaremo-nos da definição de tradução domesticadora e estrangeirizadora proposta por Lawrence Venuti na sua Teoria da Invisibilidade.
\end{abstract}

1 Graduada em Letras pela Universidade Estadual do Centro-Oeste UNICENTRO.

2 Doutoranda em Letras (UEL) e professora da Universidade Estadual do Centro-Oeste - UNICENTRO. 
PALAVRAS-CHAVE: Tradução; "Famigerado"; Teoria da invisibilidade.

ABSTRACT: The translation studies give us the possibility to answer some questions that come out when we read Guimarães Rosa's books. As readers in our culturelanguage, Rosa's book provokes us when we face his peculiar language, his different syntax and neologisms. Knowing the English language and culture a little, we ask ourselves how it would be possible to translate some challenges of Rosa's language. The aim of this analysis is to study the translation of "Notorious" tale. It was translated by Barbara Shelby in 1968. As he fragmented the linearity of the sentences to suggest a rhythm or oral discontinuity, and created a unique punctuation, how was Rosa's singularity translated into the English language? How was the translation of "Se sério, se era. Transiu-se-me" (p.15), for instance? Was his syntax noticeable in English or it got lost during the translation process? In order to try to search the answer to these questions, we will arrogate to ourselves the definition of domestic and foreign translation suggested by Lawrence Venuti in his Translator's Invisibility Theory.

KEYWORDS: Translation; "Famigerado"; Invisibility Theory.

\section{Introdução}

Ao comprar um livro ou pegá-lo numa biblioteca, vários fatores podem influenciar na escolha do leitor, como por exemplo: o autor, o título, a ilustração da capa, o assunto que the interessa. Ele nem imagina todos os processos pelos quais aquele exemplar passou para poder chegar até suas mãos. No entanto, o trabalho que envolve o lançamento de um livro por uma editora também não é um grande mistério para o leitor. Para muitos, o ato de revisar uma obra e de lançá-la no mercado editorial são suficientes para que ele tenha certeza como aquele livro foi produzido, mas dificilmente o fator tradução pesaria em sua esco-

TradTerm, 16, 2010, p. 175-192 
1ha. O trabalho de um tradutor é assim mesmo, às escuras: muitos leitores não sabem que essa é a condição essencial para as obras ultrapassarem a barreira de sua própria língua e alcançarem status universal, sendo tal trabalho considerado um instrumento de mediação entre culturas.

A atenção que é dispensada à tradução fez surgir muitos questionamentos sobre o seu processo, uma vez que não são somente signos linguísticos os transferidos para uma outra língua, mas manifestações culturais também. Porém, esse processo vai além de uma simples transferência: a atividade tradutória atrai a atenção dos críticos que se preocupam em saber como isso acontece. Questões como o que se perde e o que se ganha em cada tradução têm sido o cerne de muitas análises na área dos estudos da tradução atualmente.

$\mathrm{Na}$ literatura brasileira temos um exemplar um tanto quanto curioso. Mesmo para quem é somente um leitor da produção de Guimarães Rosa pode se questionar o quão árduo seria o trabalho daquele que se atrevesse a traduzi-lo. De fato, ler e estudar Guimarães Rosa é sempre um desafio, mas traduzi-lo se torna um desafio ainda maior devido à linguagem coloquial, à sintaxe única e os inúmeros neologismos, que marcam a sua escrita e se tornam um obstáculo no mínimo interessante para os Estudos da Tradução Literária.

Esse desafio foi tomado por Eliana Amarante, quando analisou a tradução dos neologismos na versão italiana de Grande Sertão: Veredas, e por Rodrigo Amorin, que estudou os neologismos de Sagarana na versão inglesa da obra. Contudo, os estudos da tradução de Rosa estão, na sua maioria, focalizados nas traduções do seu romance Grande sertão: veredas, deixando uma lacuna na análise das traduções dos contos do autor. A obra Primeiras Estórias (1962), na qual está presente o conto "Famigerado", teve uma única tradução para a língua inglesa, em 1968, feita por Barbara Shelby.

"Guimarães Rosa explodiu a linguagem e passou a jogar xadrez com o leitor" (Schlafman, 1998:187). Dono de uma genialidade única, Guimarães contrapõe-se a toda e qualquer afirmação categórica, a toda e qualquer certeza estabelecida. Um dos traços dessa genialidade são os seus inúmeros neologismos. 
Ele, "brincando" com as palavras, as unia às já existentes, recuperava o significado de outras, ou apenas inventada uma palavra totalmente nova. E qual seria a solução encontrada por Shelby para traduzir os neologismos contidos no conto, como por exemplo, "cabismeditado"? Indagamos se a tradutora criou um neologismo na lingua inglesa, ou se preferiu usar uma palavra já existente, com significado aproximado. Ou ainda: quem sabe manteve "cabismeditado" no texto com uma nota de rodapé?

O universo ficcional de Rosa se detém no sertão mineiro, retratando um universo longe da civilização, habitado por personagens rudes, como o jagunço. Todo esse universo que somente é encontrado lá, desperta-nos curiosidade: como foram traduzidas passagens como "(...) ele é de seu tanto esmiolado (...) pra mor de lhe preguntar a pregunta, pelo claro"? ${ }^{3}$ Terá ela tirado essa característica tão única da escrita de Rosa, ou encontrou na lingua inglesa uma forma para manter essa linguagem coloquial?

Guimarães Rosa é tido por estudiosos e críticos como um autor que operou grande transformação na sintaxe do seu tempo. Ele fragmentava a linearidade das frases para, por exemplo, sugerir a descontinuidade do tempo ou da linguagem oral, além de criar uma pontuação também única. E na tradução para a lingua inglesa, de que maneira essa singularidade rosiana foi traduzida? Como foi feita a tradução de, por exemplo: "Se sério, se era. Transiu-se-me" (p. 15)? A sintaxe rosiana se faz notável na versão em inglês ou ela se perdeu no processo da tradução?

Para nos imbricarmos na tentativa de buscar respostas a esses questionamentos, a definição de tradução domesticadora e estrangeirizadora proposta por Lawrence Venuti na sua Teoria da Invisibilidade será de importante valia. Segundo o autor,

(...) a tradução é o processo através do qual uma mensagem é decodificada a partir de uma cadeia de significantes fornecida pelo autor estrangeiro, e outra mensagem cor-

3 Durante este artigo, as passagens citadas de Guimarães Rosa são da obra Primeiras Estórias (1988). Já a tradução a que nos referimos se trata da obra The third bank of the river and other stories (1968), de Barbara Shelby.

TradTerm, 16, 2010, p. 175-192 
respondente é codificada em outra cadeia, fornecida pelo tradutor". (Venuti, 1996:113)

Isso deixa claro o caráter transformador da tradução e o papel intervencionista do tradutor.

\section{Teoria da Invisibilidade}

Para explicar a Teoria da Invisibilidade, Venuti utiliza a reinterpretação do marxismo dialético de Marx feita por Loius Althusser (1986), que percebe o processo transformacional da tradução como uma prática social, colocando três momentos no processo produtivo: a matéria prima, o trabalho de transformação e o produto final. A matéria-prima é o texto na língua-fonte; o trabalho de transformação, o ato de traduzir em si; e o produto final, o texto na língua de chegada. De acordo com Venuti, o momento-chave na prática produtiva da tradução é a relação entre a ideologia e a estratégia de tradução adotada pelo tradutor, o campo conceitual onde suas escolhas estão (Venuti, 1996:116). Por exemplo, a exigência contemporânea, que prega uma leitura fácil e fluente, está relacionada com os valores econômicos burgueses. Prefere-se uma tradução legivel e "bem-sucedida", sem trechos canhestros, estranhos e ambíguos; dessa forma seria mais "consumivel" ao mercado editorial, pois "a consumibilidade é a ideologia que media a produção de uma tradução fluente e a sua transformação em mercadoria" (idem: 117).

A fluência segue a ideologia da estratégia burguesa, enquanto a invisibilidade é estabelecida como a estratégia da resistência por ir contra as condições impostas por aqueles que dominam o mercado individual. Se o tradutor é contratado por determinada editora, pressupõe-se que ele deva seguir as normas estabelecidas pela contratante. Tal situação acentua a afirmação de que o tradutor não poderá realizar o seu trabalho de forma autônoma. Uma vez que a tradução fluente não representa nenhum obstáculo para a leitura de uma obra, ela se torna uma exigência econômica diretamente ligada à venda do produto: quanto mais fluente mais fácil de vender. Portanto, um texto pouco fluente seria responsável pelo baixo status de uma tradu- 
ção refletindo a situação cultural e econômica do seu contexto. Consequentemente, o trabalho de tradução fica à mercê de julgamentos que encobrem e subestimam o papel daquele que proporciona o contato do leitor com outra cultura através da tradução.

Revisores e editores pregam essa ideologia de consumibilidade de uma tradução fluente. Nessa ideologia, quanto menos visível o tradutor for, melhor será a tradução. Dessa maneira, a invisibilidade do tradutor é em parte um efeito estranho de sua manipulação da língua, um auto-aniquilamento que resulta do próprio ato da tradução como ele é concebido e praticado hoje (Venuti, 1996:112). O autor relembra que um texto estrangeiro sofre influências não só ideológicas, mas também estéticas, políticas e econômicas. Propõe, então, que as traduções devam soar estrangeiras, tenham um aspecto opaco, fazendo com que o leitor perceba que aquele não é o texto original. É essa opacidade que fará com que a interferência do tradutor se torne visivel, e que, dessa maneira, o leitor se aproxime do contexto social da lingua-cultura de partida (idem: 118).

O autor também afirma que a fidelidade não pode ser vista como uma igualdade linguística, já que o texto na língua-fonte está sujeito a interpretações distintas. O tradutor faz escolhas interpretativas que respondem a uma situação cultural específica tornando o texto traduzido, uma aproximação que irá transpor o texto na língua-cultura fonte. Isso não quer dizer que a tradução está sempre sujeita à liberdade, à impossibilidade, à subjetividade e ao "erro", pois, a interpretação do tradutor é limitada por um conhecimento da cultura da lingua-fonte, ainda que parcial, e por uma assimilação dos valores culturais da língua-meta (Venuti, 1996:122).

Venuti deixa claro que, apesar de ele combater a ideia da invisibilidade do tradutor, defende que a tradução é uma prática social que exige um trabalho complicado e dificil de transformação por parte do tradutor; ele não pretende promover o tradutor ao status de outro autor que venha a concorrer com ou ultrapassar o autor estrangeiro. Pelo contrário: a proposta de Venuti é a de que a atividade, tanto do autor estrangeiro quanto a do tradutor, seja influenciada por determinações sociais, materiais 
linguísticos, literários e históricos que formam seus textos, podendo promover denotações que superam suas intenções. Para Roland Barthes,

um texto não é feito de uma linha de palavras a produzir um sentido único, (...) mas de um espaço de dimensões múltiplas, onde se casam e se contestam escrituras variadas, das quais nenhuma é original: o texto é um tecido de citações, saídas dos mil focos da cultura". (Barthes, 1988 apud Venuti, 1996:123)

O pensamento de Barthes contribui para a proposta de Venuti, já que, de acordo com este, uma tradução é uma "trama de citações", e elas levam consigo ideologias, uma vez que as decisões do tradutor estão limitadas no contexto social no qual o tradutor está inserido. As traduções fluentes produzem um efeito ilusório de transparência. Esse efeito de ilusão é o que reafirma uma língua, ao excluir outras formas linguísticas e culturais, ou mascaram as características peculiares à línguacultura de partida, que deixam de ser inscritas na tradução. Dois processos tradutórios distintos podem ocorrer, então, ao se questionar o critério da fluência num texto traduzido: domesticação e estrangeirização.

O processo de domesticação do texto estrangeiro viria atender à obrigatoriedade de um texto fluente dentro de uma línguacultura de chegada, atestando o efeito de ilusão. Isso ocorre quando a tradução procura distanciar o leitor do texto original, mascarando valores culturais do texto estrangeiro, substituindo-os pelos da língua-alvo, tornando familiar, enfim, o texto traduzido.

Através do processo da tradução estrangeirizadora, o tradutor insere elementos que não são comuns à lingua-cultura de chegada. Assim, exige maior intervenção do tradutor, o que abala a lei da fluência, tornando um trabalho de tradução do tipo que distancia o leitor de sua cultura.

A esse respeito, Venuti enfatiza a inscrição de diferenças culturais e linguísticas do texto estrangeiro, cuja estratégia de tradução significa uma ruptura dos códigos culturais que continuam a existir na língua-cultura de chegada. Num contexto cul- 
tural de uma língua menor ${ }^{4}$, uma tradução estrangeirizadora atua como forma de resistência contra o etnocentrismo, racismo, narcisismo cultural e imperialismo da lingua-cultura de chegada (Venuti, 1995:20). Por isso, para o autor,

A tradução que se preocupa em limitar seu etnocentrismo não se arrisca necessariamente a ser ininteligivel e culturalmente marginal. Um projeto tradutório pode se distanciar das normas domésticas a fim de evidenciar a estrangeiridade do texto estrangeiro e criar um público-leitor mais aberto a diferenças lingüísticas e culturais, mas sem ter que recorrer a experiências estilísticas que são tão alienadoras a ponto de causarem o próprio fracasso (...) ao tentar abarcar as culturas estrangeira e doméstica bem como os públicos-leitores domésticos, uma prática tradutória não pode deixar de produzir um texto que seja uma fonte potencial de mudança cultural. (Venuti, 2002:166)

Friedrich Scheleirmacher, numa palestra sobre diferentes métodos de tradução, em 1813, aponta para o fato de que a tradução estrangeirizadora faz com que uma cultura diferente seja manifestada em outra; e ainda: o tradutor tem de fazer escolhas $\mathrm{O}$ autor, porém, reduz essas escolhas a apenas duas: "ou o tradutor deixa o autor em paz o máximo possível, e se aproxima do leitor, ou ele abandona o leitor, e se aproxima do autor" (Scheleirmacher apud Lefevere 1977:74).

Diante disso, o efeito ilusório de uma tradução fluente dá ao leitor a falsa impressão de estar lendo uma obra como se fosse o original. A tradução domesticadora, nesse sentido, mascara as condições do texto traduzido, excluindo qualquer influência de valores culturais estrangeiros. O leitor não tem contato com qualquer outro tipo de cultura, tendo a falsa impressão que todas as outras formas de cultura devem ser parecidas com a sua.

Schleiermacher afirmou, em seu artigo On the Different Methods of translating (1813), que a tradução seria uma prática importante para um movimento nacionalista, pois ela poderia

4 Este termo é utilizado por Venuti para designar o cânone literário de uma cultura dominante. (cf. Venuti, 2002:25).

TradTerm, 16, 2010, p. 175-192 
enriquecer a língua alemã ao desenvolver uma literatura de elite, o que viria a permitir que a cultura alemã percebesse o seu papel histórico dentro da dominação global. Ele acreditava que a tradução estrangeirizadora poderia auxiliar a construção de uma cultura nacional, levando a identidade cultural a se basear em outros modelos linguísticos e políticos. Para ele, o "genuíno tradutor" também seria um escritor. (Schleiermacher apud Lefevere 1977:74)

Mesmo tendo Schleiermacher defendido um modelo tradutório para tornar o seu povo mais receptivo a culturas diferentes e não permanecerem sob um imperialismo político e social, a tradução estrangeirizadora, ao preservar as diferenças linguísticas e culturais do texto estrangeiro, acaba sendo lida por um grupo restrito de leitores de uma elite educada. Portanto, pode-se afirmar que toda tradução tem um cunho etnocêntrico, pois mesmo traduzindo as diferenças, é dificil uma tradução escapar de certa hierarquia de valores culturais inscritos na lingua-cultura de chegada.

\subsection{Traduções domesticadoras na formação de identidades culturais}

A domesticação de um texto estrangeiro se estabelece como um fator de risco toda vez que é inserido numa lingua-cultura. Isto é, através do processo tradutório, um texto com determinado valor linguístico e cultural na língua-cultura de partida pode ter os seus valores linguísticos e culturais diminuídos ou, até mesmo, substituídos por outros mais fortes dentro da língua-cultura de chegada. O quanto esse texto sofrerá as influências desse fator dependerá da força da língua-cultura de chegada ou de partida.

Por um lado, a força que a língua maior exerce sobre a menor afetará diretamente o resultado final. O efeito produzido com essa abertura é evidente: a formação de identidades culturais. Isso não implica que uma língua-cultura menor seja manipulada ou que fique sob o domínio de outra. Pelo contrário, ao entrar em contato com o diferente, escolhe e retém o que a outra lingua-cultura tem de melhor e, consequentemente, aprimora sua própria língua-cultura. 
Por outro lado, a domesticação de textos estrangeiros por outras culturas pode atribuir a eles um novo status dentro do cânone literário. Com a domesticação, há o risco de se reduzir estilos de autores e traços nacionais do discurso a uma prosa simples e uniforme. A intenção de Venuti, então, é basicamente mudar os padrões de leitura, forçando o seu leitor a um reconhecimento prazeroso da tradução. Segundo Jirí Levý, traduzir é um processo de fazer escolhas (Levý, 1967 apud Venuti, 1996:113), e são as escolhas operadas por Shelby ao traduzir "Famigerado" que serão examinadas a seguir neste trabalho.

\section{Análise}

O conto "Famigerado" é um episódio cômico. Relata-se a visita que quatro cavaleiros rudes do sertão de Minas Gerais fazem a um médico do interior. Damázio, o líder daqueles homens e conhecido assassino da região, quer que o doutor the esclareça o significado da palavra "famigerado". O médico, com medo, revela o sentido da palavra, mas não aquele em que ela provavelmente foi dita, pois teme a violência de Damásio. Explica o doutor que "famigerado" quer dizer "célebre", "notório", "notável". Damázio, depois de tranquilizado com a resposta do médico, agradece e vai embora.

\subsection{A linguagem popular}

Nossa análise começa justamente com o a palavra que dá nome ao conto: famigerado. Famigerado é uma palavra na língua portuguesa com sentido ambíguo. Significa "célebre", "notável", "que tem fama", em sentido literal; porém na maioria das vezes é utilizada com sentido pejorativo, como na frase "João é um bandido famigerado". Na língua inglesa, a tradutora encontrou um equivalente, que é utilizado da mesma forma. "Notorious" também terá o sentido de "conhecido", "popular", mas com um tom negativo. No verbete do dicionário Macmillan (2007), ela aparece definida assim: famous for something bad; infamous (famoso por algo ruim; infame.).

TradTerm, 16, 2010, p. 175-192 
Quando Damázio pergunta pela primeira vez ao médico o que a palavra "famigerado" significa, o jagunço, que não sabe nem o significado nem ao certo como pronunciá-la, atrapalha-se com a sua pronúncia e, então, Rosa faz um jogo com as sílabas, criando palavras inexistentes: “_ Vosmecê agora me faça a boa obra de querer me ensinar o que é mesmo que é: fasmisgerado ...ffaz-megerado...falmisgeraldo...familhas-gerado...?” (p.15). Essa mesma troca de sílabas, criação de novas palavras e tom humorístico estão presentes na língua inglesa, senão vejamos: "And now Will you do me a good turn? Will you learn me the right meaning of northerious...motorious... mastorious... nosterrious..." (p. 223).

Damázio era um jagunço, um homem perigoso, mas pouco letrado. Suas falas representam o linguajar dos homens do sertão mineiro, com coloquialismos, arcaísmos e desvios da norma padrão. Numa das passagens, Damázio diz: "Eu vim preguntar a vosmecê uma opinião sua explicada (...)”(p. 14). A tradutora opta por não acentuar o problema com a grafia de "perguntar", mas recorre ao uso do apóstrofo; assim, o tom de informalidade do texto permanece: "I came here to ask your 'pinion 'bout a certain matter (...)" (p. 221). Já o arcaísmo "vosmecê" é tratado e traduzido apenas como a palavra "você".

Outro trecho que salienta a fala do jagunço é: "A bem. Agora, se me faz mercê, vosmecê me fale, no pau da peroba, no aperfeiçoado: o que é que é, o que já lhe perguntei?" (p. 16). Aqui não encontramos alterações como a "pregunta" da passagem anterior, mas encontramos uma fala extremamente simples e com expressões populares. Para a língua inglesa o trecho foi traduzido como: "Well, never mind that. Now if you'll kindly tell me, on the level, man to man: what does it mean, that word I asked you just now?' (p. 223). Na tentativa de tentar reproduzir essa maneira popular do jagunço, a tradutora usa uma construção verbal inapropriada. Na última parte, "that word I asked you just now?", a frase foi construída no tempo verbal do passado simples, quando deveria estar no presente perfeito. Este, porém, é um tempo verbal mais dificil de ser usado e entendido, logo não utilizado por pessoas simples como Damázio. Talvez tenha sido o recurso encontrado para marcar a coloquialidade da passa- 
gem. De todo modo, o tom humorístico trazido pela expressão "no pau da peroba" na língua-cultura fonte não encontra um equivalente na língua-cultura alvo.

O fato é que o conto é repleto de passagens com linguagem popular e, por conta disso, em diversos momentos é preciso recorrer a um dicionário para confirmar se tal palavra é um neologismo ou palavra dicionarizada mas de uso restrito, presente no vocabulário do jagunço e, consequentemente, pouco conhecida. É o caso do substantivo "invencionice", presente no seguinte trecho: " $E$ já aí outro susto vertiginoso suspendia-me: alguém podia ter feito intriga, invencionice de atribuir-me a palavra de ofensa àquele homem (...)” (p. 15). Na língua inglesa, o substantivo é transformado em verbo e traduzido como inventing things. Vejase o contexto frasal: "And here another frightful thought made me dizzy: maybe someone had wanted to stir up trouble by inventing things, saying I had insulted the man (...)" (p. 223). O mesmo acontece no trecho "Causava outra inquietude, sua farrusca, a catadura de canibal" (p. 14). A palavra "catadura", na língua portuguesa, tem o significado de "aparência, expressão do semblante". Na tradução, a passagem ficou da seguinte forma: "It got me worried again; that black stare, and the cannibal cut of him" (p. 221).

Uma passagem que merece atenção é quando o doutor descreve o visitante Damázio: "Sei desse tipo de valentão que nada alardeia, sem farroma. Mas avessado, estranhão, perverso, brusco, podendo desfechar com algo, de repente, por um és-nãoés" (p. 14). O trecho de tradução difícil é devido à palavra "farroma", que significa "bravata, fanfarrice", e da construção "és-nãoés". Na língua-cultura alvo ficou assim: "I know a thing or two about that kind of fighting man who doesn't go around boasting and talking big. Mean as the devil, but keeps the meanness bottle up and then lets fly all of a sudden because of a yes-you-are-noyou-ain't" (p. 221). Como se vê, "Farroma" transformou-se no verbo "talking big"; já o sentido da expressão "és-não-és" encontrou um equivalente que o representa bem: "yes-you-are-no-youain't”.

Em diversos momentos, a linguagem popular traz um tom humorístico ao conto, como quando Damázio descreve o "moço

TradTerm, 16, 2010, p. 175-192 
do Governo": "O rapaz, muitos acham que ele é de seu tanto esmiolado" (p. 15). Veja-se que o tom de humor já não fica nítido em inglês: "A lot of folks think that young fellow ain't got an awful lotof sense" (p. 222). Outro trecho com tom engraçado é encontrado no final do conto, na fala de Damázio, que já satisfeito com o significado e explicação do médico sobre sua dúvida, diz: " $A$ gente tem cada cisma de dúvida boba, dessas desconfianças... só pra azedar a mandioca" (p. 17). O texto em inglês perdeu o humor que tinha o original: "You get all riled up over some piece of foolishness, some little doubt... just addle your brains over nothing" (p. 225). O humor é estabelecido ao ser associado ao contexto cultural e ficar restrito a ele, o que demonstra que o trabalho de tradução vai muito além da transferência de códigos linguísticos de uma língua para outra. A tentativa de se encontrar um equivalente é válida, mas ela encontrará na língua-cultura alvo uma expressão que possa ter carga de humor associada àquele contexto.

\subsection{Os neologismos}

Uma marca reconhecida da escrita de Rosa, aliás motivo de muitos estudos acadêmicos, é a criação de neologismos. No conto, há vários deles. Cabismeditado é um exemplo. Para alguns estudiosos, a palavra seria a junção de "cabisbaixo" e "meditando". Mas a solução encontrada pela tradutora não foi também o neologismo na língua inglesa; em vez disso, traduziu como: hangdog head hanging down. Em português, a expressão significaria "um derrotado de cabeça para baixo". Aliás, a mesma palavra hangdog é usada na passagem "They appeared to be scared, cowed, hangdog lot" (p. 220). Como tradução do trecho "Semelhavam a gente receosa, tropa desbaratada, sopitados, constrangidos - coagidos, sim" (p. 13). Nessa passagem, a palavra é usada para traduzir "constrangidos". Já a palavra "sopitada" ficou sem tradução na versão em inglês.

Outro neologismo que chama atenção na obra e na sua tradução é: "Subiu em si, desagravava-se, num desfogaréu" (p.16). $\mathrm{Na}$ língua inglesa, o termo desafogaréu também não encontrou um neologismo equivalente e foi traduzido como "He was himself 
again, no longer thirsty for vengeance. The bonfire had been put out" (p. 225) que, em lingua portuguesa, significa "a fogueira tinha sido apagada". Uma tradução literal desse neologismo é praticamente impossivel; porém, ao explicar e dissolver o neologismo, a característica de Guimarães Rosa desapareceu na tradução.

Cumpre destacar, ainda, a presença do vocábulo mumumudos, usado pelo doutor para descrever os três cavalheiros que acompanhavam Damázio (daí a repetição da sílaba "mu" três vezes: uma para cada cavalheiro): "Como por socorro, espiei os três outros, em seus cavalos, intugidos até então, mumumudos" (p.16). Em inglês a solução encontrada foi traduzir o sentido de silêncio que a palavra traz: mute as mummies. Confira o trecho traduzido: "I glanced at the three men on horseback, wrapped up in themselves all the time, mute as mummies" (p. 224).

Solução parecida de tentar explicar o neologismo foi encontrada na passagem: "O homem queria estrito o caroço: o verivérbio" (p. 16). Aqui temos duas das principais características de Rosa: linguagem popular e neologismo. Na versão em lingua inglesa, a passagem não apresenta qualquer dessas duas caracteristicas, sendo traduzida como "The fellow wanted the gist and the gospel" (p. 224). Já o neologismo famanasse, presente no trecho "(...) que aqui ele se famanasse, vindo para exigir-me, rosto a rosto, o fatal, a vexatória satisfação?” (p. 15), foi integralmente omitido da tradução para a língua inglesa.

\subsection{A sintaxe}

O outro componente da obra de Rosa é a construção singular da sintaxe. Logo na abertura, na primeira frase do conto, nos deparamos com a seguinte frase: "Foi de incerta feita -o evento" (p.13). O traço, usado para criar uma pausa na leitura, não aparece na versão em língua inglesa: "It was funny the way it happened" (p.219). Note-se que, além da omissão do traço, na tradução temos a inclusão do adjetivo funny, o que faz com que o leitor leia o conto já esperando uma situação engraçada. Essa prévia, contudo, não existe na língua-cultura-fonte. O leitor, então, descobre essa característica no decorrer de sua leitura sem sofrer nenhuma influência.

TradTerm, 16, 2010, p. 175-192 
Em algumas passagens, a tradutora encontrou uma solução para manter a pontuação de Rosa. É o caso de "oh-homemoh" (p. 13), e de "E, pá" (p. 15), ocorrências traduzidas como "man-oh-man" (p. 219) e "And then, bang" (p. 222), respectivamente. Porém, em outras passagens isso não se fez presente.

A pontuação pode ser considerada algo natural e comum; pode até passar despercebida, mas não no texto de Guimarães Rosa. De fato, a abundância de vírgulas, pontos e travessões marcam a sua escrita. É o que se observa em "Se sério, se era. Transiu-se-me" (p. 15), traduzido como "It was a serious business, all right. I was frozen to the spot" (p. 223). Ressalta-se que esse procedimento desaparece no trecho "Com arranco, calou-se" (p. 15). O trecho foi traduzido como um texto corrido, sem a pausa presente no texto em língua portuguesa "All of a sudden He pulled up short" (p. 222). Importa destacar que, embora a pontuação no primeiro caso tenha sido respeitada, tanto neste quanto no segundo caso o rearranjo das palavras proposto por Guimarães Rosa não é mantido na língua inglesa.

Uma passagem é digna de comentário: "O medo é a extrema ignorância em momento muito agudo. $O$ medo $O$. O medo me miava" (p. 14). Aqui, nota-se que o medo não se refere apenas ao sentimento, já que o "O" é uma das maneiras como o jagunço se refere ao diabo. Segundo João Adolfo Hansen (2000:90), o "O" é também um dos nomes do Diabo, um artigo determinante elevado à classe de nome. Já na língua-cultura alvo, o medo é tratado apenas na extensão do sentimento, como um medo muito grande: "Fear is knowing how ignorant you are when you're in a jam Fear with a capital F was screeching around inside me" (p. 220). Perde-se, pois, a característica cultural do jagunço que, de acordo com sua cultura, rege a sua vida na eminência da existência (ou não) do diabo.

\section{Considerações finais}

O trabalho do tradutor é um trabalho quase injusto, pois sempre está sujeito a críticas, sendo julgado em termos de se traduz demais ou se traduz de menos; se acrescenta algo que não havia no texto original ou se retira algo que ali estava. Pare- 
ce não existir, assim, uma medida precisa para tal tarefa. E é aí que está o seu grande desafio: qual é essa medida?

Guimarães Rosa é tido como um dos grandes autores do seu tempo. No Brasil, é comparado a Machado de Assis e, fora, a James Joyce, por sua genialidade e linguagem singular. E é devido a essa tarefa árdua que é a tradução, que muitos críticos de outras culturas encontraram em Rosa um afã quase que inesgotável de possibilidades.

Com base na Teoria da Invisibilidade de Venuti (1995) que distingue duas formas de tradução-domesticadora x estrangeirizadora -, podemos considerar a tradução do conto "Famigerado" para a língua-cultura inglesa como uma tradução domesticadora.

A leitura do conto na lingua-cultura de partida, conforme demonstramos na análise, é uma leitura truncada, cheia de arcaísmos, neologismos. Há, além disso, o uso da linguagem popular do jagunço do interior de Minas, um sujeito distante da maioria dos leitores de Rosa dentro de sua própria língua-cultura. É, pois, uma leitura que nos faz constantemente procurar o dicionário para verificar se estamos nos deparando com um outro neologismo rosiano ou apenas uma palavra desconhecida do nosso vocabulário.

Além disso, essa linguagem tão peculiar das personagens de "Famigerado" acaba conferindo um tom humorístico ao conto. O humor, em passagens como "O homem queria estrito o caroço: o verivérbio", conforme apontamos atrás, perdeu sua graça quando traduzido para "The fellow wanted the gist and the gospel". Ora, um leitor de lingua inglesa lendo "Notorious" não poderia dizer que o autor do conto é conhecido pelos seus neologismos, pois eles desapareceram na lingua-cultura alvo. No lugar deles encontramos explicações do que eles "parecem" significar. Um exemplo disso é o neologismo mumumudos, que além de ser neologismo, é uma palavra engraçada devido à repetição da sílaba "mu". Acresce-se que existem neologismos não traduzidos, que foram absolutamente ignorados na tradução, como no caso de famanasse.

Vemos, então, que traduzir é mais do que escolher palavras e termos equivalentes. Na verdade, a tradução exige um 
conhecimento profundo não só da língua, mas também da cultura de partida. Para a tradução de Guimarães Rosa, então, é fundamental entender a cultura em que o sertanejo, por exemplo o Damázio, e o doutor estão inseridos. Contudo, num dos trechos do conto traduzido percebe-se o não-conhecimento dessa cultura pelos tradutores. Isso fica evidente quando, por exemplo, o doutor fala do medo devido à presença daquele assassino à sua porta - O medo O. O medo me miava. Como já mencionado na análise, não se trata apenas do sentimento de medo. Já para a tradução parece que se trata sim.

A tradução ficou restrita à língua de partida, deixando o elemento cultural de fora. É bem verdade que a domesticação do texto no ato da tradução não alterou significativamente a compreensão e entendimento do mesmo. Contudo, o que foi domesticado é justamente aquilo que o autor tem de mais precioso e valorizado: sua linguagem ímpar. Rosa foi um dos inovadores da linguagem. E, é exatamente essa linguagem que deveria ser a preocupação primordial de qualquer trabalho de tradução de Guimarães Rosa. Acreditamos que essa não seja tarefa fácil, uma vez que a própria leitura em sua língua-cultura de partida, por um falante de língua portuguesa, é dificil; mas exatamente por esse motivo é que não poderia ser diferente na língua inglesa.

A força que a língua maior, nesse caso a inglesa, exerce sobre a menor de fato afetou diretamente o resultado final. Não houve, como preconizou Venuti (2002), uma abertura à formação de identidades culturais. Percebemos, então, que nesse caso a língua-cultura menor foi sim manipulada, esteve sob o domínio de outra. Se o contrário tivesse ocorrido, teria sido propiciado um contato com o diferente, com o que a outra língua-cultura tem de melhor e, consequentemente, poderia aprimorar a lingua-cultura de chegada.

A domesticação do texto de Rosa pela outra língua-cultura dispôs sua obra ao risco de ser reduzida a estilos de autores e traços nacionais do discurso a uma prosa simples e uniforme. A missão de traduzir autores como Guimarães Rosa teria mais sucesso se fosse realizada por dois tradutores - um do português e outro do inglês. Talvez fosse imprescindivel que ocorresse a troca de marcas culturais, pois a carga cultural contida em 
Rosa não consegue ser transposta para outra língua-cultura somente com a substituição de signos linguísticos sem a companhia de seu signo cultural.

Além do aspecto cultural, as marcas da escrita de Rosa causam estranhamento para o leitor na sua própria língua-cultura; para os de outra língua é um desafio ainda maior. Também por conta disso, a construção atípica de frases, a recorrência de neologismos, pontuação ímpar serão sempre um desafio para qualquer leitor, independente de sua nacionalidade. Assim, a tentativa de se fazer tal trabalho de tradução já é motivo de admiração, e sua efetivação, um desafio que merece reconhecimento.

\section{Referências bibliográficas}

HANSEN, J. A. (2000) O o: a ficção da literatura em Grande Sertão: Veredas. São Paulo: Hedra.

LEFEVERE, A. (1977) Translating literature: The German tradition from Luther to Rosenzweig. Assen: Van Gorcum.

MICHAEL, R. (2007) Macmillan English dictionary for advanced learners. $2^{a}$ ed. Oxford: Macmillan.

ROSA, G. (1988) Primeiras Estórias. Rio de Janeiro: Editora Nova Fronteira, $33^{\mathrm{a}}$ ed.

(1968) The third bank of the river and other stories. New York: Knopf. Trad. Barbara Shelby.

SCHLAFMAN, L. (1998) A verdade e a mentira: novos caminhos para a literatura. Rio de Janeiro: Civilização Brasileira.

SOARES, A. (2008) A falta que falta. Grande Sertão Veredas e a Subversão do Satã. Anais do XI Congresso Internacional da ABRALIC. São Paulo: USP. Disponivel em <http://www.abralic.org.br/cong2008 /AnaisOnline/simposios/pdf/054/ANDREI_SOARES.pdf> Acesso em 26 de setembro de 2009.

VENUTI, L. (1995) The translator's invisibility: a history of translation. London and New York: Routledge. (1996) A invisibilidade do tradutor. Palavra 3. Rio de Janeiro: Grypho, pp. 111-134.

(2002) Escândalos da tradução: por uma ética da diferença. Bauru, SP: EDUSC. Trad. Laureano Pelegrin, Lucinéia Marcelino Vilela, Marileide Dias Esquerda e Valéria Biondo.

TradTerm, 16, 2010, p. 175-192 